\title{
Engaging undergraduates with research to promote cumulative learning
}

Connor, Andy M.

Auckland University of Technology,New Zealand (andrew.connor@aut.ac.nz)

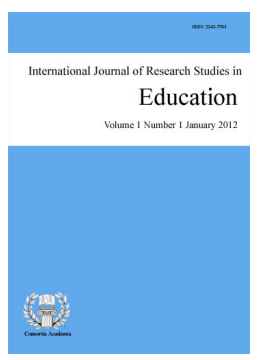

ISSN: $2243-7703$

Accepted: 1 August 2016 Online ISSN: 2243-7711

OPEN ACCESS

\section{Abstract}

This paper argues that academia is undergoing a crisis, particularly in terms of some institutions experiencing growing student disengagement. Many changes to curriculum design and delivery have been focused on the modularisation of degree programmes to promote greater flexibility for a changing student demographic. This paper suggests that modularisation has the potential to create segmented learning, where students learn particular content in isolation and do not create linkages between knowledge gained across different modules. It is suggested that blurring boundaries between modules can address concerns about segmentalism. It is also suggested that blurring boundaries between other academic structures can also add value, for example the distinction between teaching and research. This paper presents a number of examples of work-in-progress strategies for using the creation of a third space of learning where research is used to generate cumulative learning.

Keywords: curriculum design; interdisciplinary education; modularisation; academic practice; third spaces; cumulative learning 


\section{Engaging undergraduates with research to promote cumulative learning}

\section{Introduction}

It is arguable that academia is in crisis, and whilst such claims are not new (Altbach, 1997) there is growing evidence that suggests a number of issues are converging that potentially will upset academic norms. Côté and Allahar (Côté \& Allahar, 2007) outline a number of such issues including growing disengagement in the student body and increasing conflicts in terms of the role of academic staff. Such issues are well recognized and some authors go as far to suggest that we are experiencing the emergence of a "new normal" for academia and that Universities need to change to embrace this state (Tierney, 2014).

In its own way, academia is a complex "system of systems", where emerging and shifting states and contexts dictate that any element of an academic crisis will have a range of possibilities for addressing the problem that may produce unforeseen impact in other elements of the crisis. This presents a major challenge for Universities as addressing the perceived crisis through well understood mechanisms may result in further unforeseen negative outcomes. It has also been argued by some authors that certain disciplines are also in a crisis, for example (Bremner \& Rodgers, 2013) suggest that there is a blurring of the boundaries between traditional design disciplines producing a new capacity for collaboration that has encouraged new types of design practice to emerge (Atkinson, 2010). This phenomenon is not restricted to design and can be seen in many other practice oriented disciplines.

This paper suggests that engendering such a blurring of the boundaries in academia may also allow new types of academic practice to emerge that alter some of the underlying aspects of the academic crisis. This paper is organized as follows. Section 2 provides context for the paper by considering the emergence of segmented learning in academia. Section 3 outlines a justification for the blurring of academic boundaries, whereas Section 4 describes a number of specific strategies that result in blurred boundaries and discusses their effectiveness. Section 5 concludes the paper with a discussion of future directions.

\section{Literature review}

Modular degrees are now so widespread that they are considered the normal mode of delivery for higher education. Modularization emerged in the late 1960s and gained momentum through to the early 1990s, where in the UK the modularization of the higher education curriculum was implemented in all but a handful of universities (Bridges, 2000). The rise of modular curricula has been documented in a number of international locations (Bell \& Wade, 1993; Crossley, Clarke, Tabi, \& Thomas, 1993) and whilst there are many different flavors of modular degrees, all are based on the philosophy that teaching and learning activities can be quantified and that units of instruction can be defined, measured and evaluated in terms of size, equivalence and learning outcomes (Bell \& Wade, 1993).

The adoption of modularized degrees has generally been motivated by broadly similar reasons, including the need to cater for more diverse student populations, to minimize the duplication of teaching and to increase opportunities for interdisciplinary study (Yifeng, 2006). Modular programs also allow students a greater of freedom in terms of personalizing their degree. As a result, modular degrees are generally designed to allow students an appropriate degree of choice in managing their own studies (Betts \& Smith, 1998).

The transition from traditional to modularized delivery was not an easy one. Early adoption of modular degrees produced an outcry, with a swathe of academics foretelling the doom and gloom to come. It has been observed that during the transition that the academic body, either because of a profound failure of communication or because of a visceral will to resist by concerted bafflement, remained unconvinced that any persuasive case had been made to adopt modular approaches (Rich \& Scott, 1997). Even after implementation, 
some authors have noted problematic issues such as structural flaws (Billing, 1996). Issues with modularization still arise in more recent studies, for example Barnett and Coate highlight a possible absence of "curriculum" as an integrating factor which suggests that course modules exist independently of each other and do not create a unified whole (Barnett \& Coate, 2004). Whilst the intensity of debate over modularization has diminished, relatively recent surveys still suggest that the whole process of transition was at least in part motivated by a "misunderstanding of classical economics on the part of neo-liberal higher education administrators" (Milliken \& Colohan, 2000).

Typically cited concerns with modular programs is that unwisely chosen modules can yield an intellectually fragmented (Jenkins \& Walker, 2014) or incoherent (Bell \& Wade, 1993) degree. Whilst such concerns may be dismissed by some as historical, more recent publications also raise concerns over corrosion of learning in modular programs (Naidoo \& Jamieson, 2005). In general, these concerns can all be considered as variations of segmentalism, where students learn skills or ideas that are connected to the context in which the skills are acquired. This generally produces problems where students struggle to transfer such learning to a different context or use the knowledge as a foundation to build further knowledge (Maton, 2009).

However, many authors argue that modularization is an improvement over "traditional rather idiosyncratic study programs" (Bleiklie, 2005), however it is worth considering the advantages of these idiosyncrasies. For example, many modern degrees include first year modules in the GPA calculation for the student and the emphasis on transcripts rather than final outcomes is obvious. In contrast, more traditional degree structures excluded the first year and heavily weighted examinations in the final year to determine the award of the degree. Whilst it might be argued that such emphasis on final examinations is unfair, the counter argument is that such a structure allows students to explore themselves and transition from school to university with no penalty placed upon such a transition and can utilize this time to learn how to learn.

It has also been observed that "teachers teach as they were taught" (Lunenberg, Korthagen, \& Swennen, 2007) and increasingly the educators teaching in modular systems also learned about their discipline in such a manner of delivery. Whilst there are clearly many advantages to modular approaches in tertiary education, other approaches also have their merits. With the new wave of educators not having experienced year long, integrated building blocks in their education, there is a need to explicitly bring to the fore the limitations of modular education and its potential role in the academic crisis. Not so as to reject modular approaches, but instead to ensure that segmentalism does not become accepted by default and that students are exposed to knowledge in such a way that they can create linkages between what they learn in different modules and engage in a new model of academic practice that has the potential to change the course of the academic crisis. Such linkages over time would be considered to be cumulative learning (Maton, 2009) where new knowledge builds on and integrates past knowledge to give new meanings to existing abilities.

\section{Blurring boundaries}

A University can be defined as an institution of higher (or tertiary) education and research which grants academic degrees in a variety of subjects and provides both undergraduate and postgraduate education. In practice, this often results in the situation where an academic is expected to make a contribution in the three traditional pillars of academia: teaching, research and service. Research has shown that at best there exists a tension between these pillars (Serow, 2000), whilst other authors go as far as to suggest that claim that universities exist for teaching and research seems incontrovertible as no real relationship exists between these two activities (Hattie \& Marsh, 1996). In many Universities this suggests that perhaps research and teaching may exist in different "spaces" of activity with little or no overlap. Whilst such a differentiation of activity cannot be directly attributed to modularized curricula, it can be argued that modular programmes extend this differentiation by limiting the extent to which students are immersed in the whole University environment. In particular, students are displaced from and have limited perception of the research interests and aspirations of both academic staff and the University itself. 
This situation therefore begs a question whether the activities of teaching and research can be translated into a new third space. Such arguments have been presented in the literature (Trowler \& Wareham, 2007) with suggestions that it is possible for teachers and learners to do research together. However, one of the identified drawbacks of this approach is that curriculum coverage can become sparse and learning slower than with more traditional delivery approaches. A wide range of reconceptualizations of the teaching-research nexus exist, but little practical guidance is available on how to implement such thinking. It is arguable that no single approach will be fruitful when deployed inside traditional academic structures and that a number of strategies need to be employed in parallel to simultaneously blur the boundaries between traditional academic structures and to create a third space. Such third spaces are emerging in academia but again most examples are staff centric (Whitchurch, 2008) rather than encompassing undergraduate students. This paper explores whether the development of new initiatives should be guided by a number of questions. These include whether undergraduate students can become engaged in research and in doing so improve their understanding of topics in the wider curriculum, and also whether staff can engage in student projects as a participant instead of a mentor to mutual advantage.

Whilst the concept of a teaching-research nexus provides a useful framework for reconsidering how to engage undergraduate students in a different style of learning, there are issues that may impact the success of such approaches. Historically, it has been noted that there is a separation between teaching and research with "with full time research staff in one corner, some teaching staff off in one corner and only slightly guided, if at all, by the results of recent research" (Clark, 2003, p. 301). More recently, there are concerns over whether the divide between teaching and research is widening as a result of research performance evaluations (Leisyte \& Dee, 2012) and suggestions that whilst this gap is acknowledged that institutions allow the pattern of labour division to persist (Geschwind \& Broström, 2015). The challenges placed on academic staff to extend their research productivity leads to a suggestion to delineate categories of staff according to their allocations of time to teaching and research (Briggs, 2016). Such suggestions will continue the shift away from the classical Humboldtian model of the unity of teaching and research within the role of an academic and potentially perpetuate the divide between teaching and research. Whilst the existence of the teaching-research nexus can be questioned, studies typically focus on finding a relationship between good teaching and productivity in research (Marsh \& Hattie, 2002). Whether or not such a relationship exists, there is a growing body of evidence that suggests that these two activities can be considered as complementary practices with the shared goal related to the advancement of learning and knowledge (Light \& Calkins, 2015). In particular, it has been seen that engaging students in research activity aligned with staff research changes the perception of value of a given degree programme as well as stimulated interest in the subject and improve understanding of methodologies employed (Fuller, Mellor, \& Entwistle, 2014).

Such approaches may be considered as research-led teaching, which is generally defined as teaching where "the content of the teaching is informed by the discipline-related research of staff themselves and that of others in the field" (Spiller, 2012, p. 3). However, the adoption of research-led teaching does not necessarily address issues related to segmented learning though a range of benefits to students have been identified, which include increased confidence and the development of transferable skills (Hajdarpasic, Brew, \& Popenici, 2015). Expanding the scope of research beyond that of academic staff, for example through the inclusion of community and industry, can further extend the value to students with specific centres based around living lab concepts identifying value to both undergraduate and graduate students (Karmokar, Connor, \& Sosa, 2015; Krogstie, 2012; Li, Sun, \& Zhang, 2009; Mott, 2014). Whilst there is clearly significant value in engaging students in research, there is little specific guidance in the literature as to how to do this, particularly in terms of developing an approach to address potentially segmented learning. The following section outlines experiences to date deploying different strategies to engage students in research activity to promote cumulative learning.

\section{Strategies for promoting cumulative learning}

This section outlines experiences of a number of strategies intended to blur the boundaries between undergraduate students, academic staff, teaching and research. Whilst the initiatives exist within a modularized 
education structure, each initiative is designed to challenge the common perceptions of such structures and promote the emergence of a new third space of learning.

\subsection{Educational context}

The Bachelor of Creative Technologies (BCT) degree is offered by Colab, a unique academic unit at Auckland University of Technology. The unit is a research-teaching nexus or "collaboratory" at the intersection of existing discipline-based programmes in art, design, communication studies, engineering, computer science and mathematics. Colab exists to develop new experimental alliances, research collaborations and learning experiences across these overlapping disciplines.

The BCT is seen as a key enabler of this goal. The flexible and experimental project-organised curriculum draws on philosophical notions of play, community and interaction to promote divergent thinking and to break, blur or transcend normative disciplinary boundaries. However, such project-based curriculum has been seen to still be prone to produce segmented learning, despite a strong focus on critical reflection, as students progress from project to project without considering how knowledge gained from previous projects can be used to inform and develop stronger outcomes. In some cases, this results in projects being undertaken "for the sake of the project" without the realisation that the project should have a greater context.

In 2013, a major curriculum revision embedded a number of key developmental steps into core courses in the degree with the intention of strengthening the foundations for inquiry-based learning. In the first semester of study, students are encouraged to reflect on their own context and aspirations. In their second semester, students are introduced to traditional knowledge structures associated with disciplinary thinking and starting to draw upon this knowledge to inform their projects. In the third semester of study, students undertake a research methods paper that encourages students to articulate projects through a guiding question. These core courses provide the basis from which it becomes possible to utilise engagement with research as a means to bridge the contexts in which students are gaining knowledge and promote cumulative learning. A number of strategies are being deployed to determine the effectiveness of this engagement.

\subsection{Research practicum}

The Research Practicum was introduced as a curriculum innovation to allow undergraduate students to undertake specific research projects and further their understanding of research approaches introduced in preceding core papers. The course challenges a number of academic norms including the delivery model which does not include timetabled contact time, which immediately erodes the compartmentalized approach to delivering classes and staff availability. An individual student petitions a member of academic staff to support a student-driven research project, and contact time is negotiated between the student and the mentor. The course works best when students align a research project alongside other academic work and assessments are allowed to cross-inform the courses in which the student is enrolled. One such project is described here where a student undertaking a Research Practicum utilized the knowledge gained through undertaking a research activity to improve their final year project work. This is a particularly interesting example as it also covers other elements of blurring across academic structures, such as allowing assessments to stretch across multiple courses and mixing students from different year groups in team based work, both of which have been adopted as strategies for improving the learning experience (Connor, Karmokar, \& Whittington, 2015).

The overall project was conducted by two students, one in their second year and one in their third year of study. The students were enrolled in different core project courses that are designed to allow students from different year groups to work together. The project evolved from one student's interest in the changing relationship between humans and objects. The second student was mostly interested in game development. By actively discussing potential overlaps in two very different interests, the student elected to develop a game controller that immersed the player physically in the game by facilitating a two-way data exchange. As well as 
controlling the game play, the controller provides haptic feedback based on game events.

From an education perspective, this project is an interesting case as the use of vertical orientated delivery allows more experienced students to provide guidance and support to less experienced ones. Guidance was provided to the team using multiple pathways. The third year student was enrolled in the Research Practicum course and provided with insight into the research process and guided through the conduct of a systematic literature review that was used to inform the development of the final haptic device by the team. The research practicum was particular effective as it nurtured the peer learning process and also led to the publication of a research paper (Foottit, Brown, Marks, \& Connor, 2016) demonstrating benefits to both the students and the staff involved. Allowing a vertically orientated delivery, stretching projects across multiple courses and encouraging undergraduate students to engage in rigorous research has create a unique blurring between undergraduate, postgraduate and staff that is effective in both driving learning and generating research momentum

\subsection{Skunkworks}

The term "Skunkworks" emerged from Lockheed Martin during the Second World War to as an alias for Lockheed Advanced Development Projects which were undertaken outside of normal business practice, though the term has been since widely used in business, engineering, and technical fields to describe a group within an organization given a high degree of autonomy and unhampered by bureaucracy. A Skunkworks project is therefore a project typically developed by a small and loosely structured group of people who research and develop a project primarily for the sake of innovation.

Whilst a number of Skunk Works initiatives have been developed in academia, most are focused on promoting research innovation utilizing academic staff. Only a very few, such as the InWorks programme at the University of Colorado, are focused on including undergraduate students. However, the Skunkworks implementation discussed in this paper differs significantly from other approaches in that it specifically addresses learning in a "third space" that exists outside of both the curriculum and research labs. In this context, the term third space is used to mean both outside of formal teaching and research activities. Skunkworks is an exercise in co-location and co-creation, where students and staff work together on jointly conceived projects that are both learning opportunities for the students and research momentum for staff.

A wide range of such projects are currently in development, examples of which include gamification of rehabilitation using mobile devices, an interactive storytelling project and the design of an active game space to promote social interaction through physical play. This initiative is currently in its first trial and no formal evaluation or critical reflection has yet been conducted. However, a number of interesting occurrences have taken place that provides early indication that the initiative has the potential to not only create new mechanisms of student engagement but also to develop new learning opportunities for students. The most notable, and unexpected, occurrence is the emergence of student-led workshops where students are offering tutorials to introduce other students to new skills and knowledge. This is another example of peer learning which seems to offer considerable potential in terms of promoting student engagement.

\subsection{Student organized conference}

The Skunkworks initiative has shown some successes in terms of engaging student and staff in co-creation projects, and in combination with embedding research and inquiry into the curriculum has resulted in a student cohort both interested and engaged in research-based activities. However, this situation has highlighted the fact that undergraduate students are generally disconnected from staff research interests. To this end, current students are in the process of organising a conference where staff submit papers to be reviewed and critiqued by the students, and later presented (if accepted!) to the entire student cohort. In this project, students are gaining an understanding not only of staff research interests but also how this research contributes to the overall goals of Colab and the University. It is expected that the conference will create a conversation around research, and 
generate further interest in research practicums and further postgraduate study.

\section{Further work}

The current initiatives in using research as a vehicle to promote cumulative learning are grounded in an understanding of third space learning and apprenticeship models of learning. Such approaches are known to be effective in breaking down silos in education (Swap \& Wayland, 2013) and anecdotal evidence suggests that the strategies are creating a student cohort that are more engaged in their own learning. However, further work is needed to formalise this anecdotal evidence and develop measures for determining the degree to which student become life-long learners and demonstrate cumulative learning. Future studies could focus not just on the extent to which segmentalism is addressed by certain strategies, but also whether there are influencing factors based on the type of University or the countries or cultures in which the strategies are deployed. It has been noted that there are a number of challenges in transitioning ideas across cultures in education (Magee, Leong, Jin, Luo, \& Frey, 2012)

In particular, there is a question whether strategies to promote cumulative learning have a particular role to play in the emergence of "education hubs". Driven by the internationalisation of teaching and research, education hubs attempt to build a critical mass participants who, thorough interaction and in some cases colocation, engage in education, training, knowledge production, and innovation initiatives (Knight, 2011). Such hubs are becoming particularly of interest in Asia (Knight \& Morshidi, 2011; Sidhu, Ho, \& Yeoh, 2011) and offer a potential mechanism to reconsider the combination of teaching and research.

\section{Conclusions}

Many academic institution are experiencing growing disengagement in the student body and increasing conflicts in terms of the role of academic staff. The exact causes of such issues are difficult to pinpoint and it is most likely that many factors come together to create a complex environment which requires new modes of thinking to facilitate change. Whilst there is no causal link between modularization of curricula and growing disengagement, there is potential that the creation of new "third spaces" of learning have the potential to improve engagement. This paper has outlined two initiatives that are part of a journey for creating such third spaces of learning by blurring boundaries between courses in a modular curriculum, between students and staff, and finally between research and teaching. These initiatives are in their infancy but experiences to date suggest that student engagement can be improved though further work is required to quantify this insight.

\section{References}

Altbach, P. G. (1997). An international academic crisis? The American professoriate in comparative perspective. Daedalus, 126(4), 315-338.

Atkinson, P. (2010). Boundaries? What boundaries? The crisis of design in a post-professional era. The Design Journal, 13(2), 137-155. http://dx.doi.org/10.2752/175470710X12735884220817

Barnett, R., \& Coate, K. (2004). Engaging the curriculum. McGraw-Hill International.

Bell, G. H., \& Wade, W. (1993). Modular course design in Britain: some problems, issues and opportunities. Journal of Further and Higher Education, 17(1), 3-12. http://dx.doi.org/10.1080/0309877930170101

Betts, M., \& Smith, R. (1998). Developing the credit-based modular curriculum in higher education. Psychology Press.

Billing, D. (1996). Review of modular implementation in a university. Higher Education Quarterly, 50(1), 1-21. http://dx.doi.org/10.1111/j.1468-2273.1996.tb01687.x

Bleiklie, I. (2005). Organizing higher education in a knowledge society. Higher Education, 49(1-2), 31-59. http://dx.doi.org/10.1007/s10734-004-2913-7

Bremner, C., \& Rodgers, P. (2013). Design without discipline. Design Issues, 29(3), 4-13. http://dx.doi.org/10.1162/DESI_a_00217 
Connor, A. M.

Bridges, D. (2000). Back to the future: The higher education curriculum in the 21 st century. Cambridge Journal of Education, 30(1), 37-55. http://dx.doi.org/10.1080/03057640050005762

Briggs, S. (2016). Teaching and research: Challenges for academic staff. Pacific Conservation Biology, 22(1), 1-2. http://dx.doi.org/10.1071/PCv22n1_ED

Clark, B. (Ed.). (2003). The research foundations of graduate education. Berkeley, CA: University of California Press.

Connor, A. M., Karmokar, S., \& Whittington, C. (2015). From STEM to STEAM: Strategies for enhancing engineering \& technology education. International Journal of Engineering Pedagogy, 5(2), 37-47. http://dx.doi.org/10.3991/ijep.v5i2.4458

Côté, J. E., \& Allahar, A. L. (2007). Ivory tower blues: A university system in crisis. Toronto: University of Toronto Press.

Crossley, M., Clarke, G., Tabi, T., \& Thomas, H. (1993). Implementing the process of modularisation in higher education: Some trans-national issues. Higher Education Quarterly, 47(4), 334-356. http://dx.doi.org/10.1111/j.1468-2273.1993.tb01633.x

Fisher, D., Bagiati, A., \& Brisson, J. (2014). The SUTD-MIT Global leadership programme: Attempting institutional transplantation through cross-cultural student leadership development. In Proceedings of the European Society for Engineering Education-SEFI 2014 Annual Conference, Birmingham, UK.

Foottit, J., Brown, D., Marks, S., \& Connor, A. M. (2016). Development of a wearable haptic game interface. EAI Endorsed Transactions on Creative Technologies, 3(6), e5. http://dx.doi.org/10.4108/eai.25-4-2016.151165

Fuller, I. C., Mellor, A., \& Entwistle, J. A. (2014). Combining research-based student fieldwork with staff research to reinforce teaching and learning. Journal of Geography in Higher Education, 38(3), 383-400. http://dx.doi.org/10.1080/03098265.2014.933403

Geschwind, L., \& Broström, A. (2015). Managing the teaching-research nexus: Ideals and practice in research-oriented universities. Higher Education Research \& Development, 34(1), 60-73. http://dx.doi.org/10.1080/07294360.2014.934332

Hajdarpasic, A., Brew, A., \& Popenici, S. (2015). The contribution of academics' engagement in research to undergraduate education. Studies in Higher Education, 40(4), 644-657.

http://dx.doi.org/10.1080/03075079.2013.842215

Hattie, J., \& Marsh, H. W. (1996). The relationship between research and teaching: A meta-analysis. Review of Educational Research, 66(4), 507-542. http://dx.doi.org/10.3102/00346543066004507

Jenkins, A., \& Walker, L. (2014). Developing student capability through modular courses. Routledge.

Karmokar, S., Connor, A. M., \& Sosa, R. (2015). From spheres towards spaces in design and creative technology. In 10th European Conference on Innovation and Entrepreneurship: ECIE 2015 (p. 349). Academic Conferences and Publishing Limited.

Knight, J. (2011). Education hubs: A fad, a brand, an innovation? Journal of Studies in International Education, 15(3), 221-240. http://dx.doi.org/10.1177/1028315311398046

Knight, J., \& Morshidi, S. (2011). The complexities and challenges of regional education hubs: Focus on Malaysia. Higher Education, 62(5), 593-606. http://dx.doi.org/10.1007/s10734-011-9467-2

Krogstie, J. (2012). Bridging research and innovation by applying living labs for design science research. In Scandinavian Conference on Information Systems (pp. 161-176). Springer. http://dx.doi.org/10.1007/978-3-642-32270-9_10

Leisyte, L., \& Dee, J. R. (2012). Understanding academic work in a changing institutional environment. In J. C. Smart \& M. Paulsen (Eds.), Higher Education: Handbook of Theory and Research (Vol. 27, pp. 123-206). Dordrecht: Springer. http://dx.doi.org/10.1007/978-94-007-2950-6_3

Li, H., Sun, Y., \& Zhang, S. (2009). Cultivation of innovative and entrepreneurial undergraduates based on the concept of Living Lab: Theory and practice. In Scalable Computing and Communications; Eighth International Conference on Embedded Computing, 2009. SCALCOM-EMBEDDEDCOM'09. International Conference on (pp. 526-528). IEEE. http://dx.doi.org/10.1109/EmbeddedCom-ScalCom.2009.102 
Engaging undergraduates with research to promote cumulative learning

Light, G., \& Calkins, S. (2015). The experience of academic learning: uneven conceptions of learning across research and teaching. Higher Education, 69(3), 345-359. http://dx.doi.org/10.1007/s10734-014-9779-0

Lunenberg, M., Korthagen, F., \& Swennen, A. (2007). The teacher educator as a role model. Teaching and Teacher Education, 23(5), 586-601. http://dx.doi.org/10.1016/j.tate.2006.11.001

Magee, C. L., Leong, P. K., Jin, C., Luo, J., \& Frey, D. D. (2012). Beyond R\&D: What design adds to a modern research university. International Journal of Engineering Education, 28(2), 397-406.

Marsh, H. W., \& Hattie, J. (2002). The relation between research productivity and teaching effectiveness: Complementary, antagonistic, or independent constructs? Journal of Higher Education, 73(5), 603-641. http://dx.doi.org/10.1353/jhe.2002.0047

Maton, K. (2009). Cumulative and segmented learning: exploring the role of curriculum structures in knowledge-building. British Journal of Sociology of Education, 30(1), 43-57. http://dx.doi.org/10.1080/01425690802514342

Milliken, J., \& Colohan, G. (2000). Managing change in higher education: assessing staff perceptions of the impact of semesterization. Higher Education in Europe, 25(4), 539-549. http://dx.doi.org/10.1080/03797720120037886

Mott, J. H. (2014). A3IR-CORE at Purdue University: An innovative partnership between faculty, students, and industry. Journal of Aviation/Aerospace Education \& Research, 24(1), 27-40.

Naidoo, R., \& Jamieson, I. (2005). Empowering participants or corroding learning? Towards a research agenda on the impact of student consumerism in higher education. Journal of Education Policy, 20(3), 267-281. http://dx.doi.org/10.1080/02680930500108585

Rich, T., \& Scott, C. (1997). Modularization and semesterization: ringing the changes. Perspectives, 1(3), 70-76. http://dx.doi.org/10.1080/1360318970010302

Serow, R. C. (2000). Research and teaching at a research university. Higher Education, 40(4), 449-463. http://dx.doi.org/10.1023/A:1004154512833

Sidhu, R., Ho, K.-C., \& Yeoh, B. (2011). Emerging education hubs: The case of Singapore. Higher Education, 61(1), 23-40. http://dx.doi.org/10.1007/s10734-010-9323-9

Spiller, P. (2012). Research and teaching. University of Waikato. Retrieved from http://www.waikato.ac.nz/tdu/pdf/booklets/6_ResearchandTeaching.pdf

Swap, R. J., \& Wayland, K. (2013). Working across disciplines and chipping away at silos with SLCE: an interdisciplinary approach to educating science and engineering students [Special edition]. International Journal for Service Learning in Engineering, Humanitarian Engineering and Social Entrepreneurship, 120-136.

Tierney, W. G. (2014). The Disruptive Future of Higher Education. In W. G. Tierney (Ed.), Postsecondary play: The role of games and social media in higher education (pp. 21-44). Baltimore, MD: Johns Hopkins University Press.

Trowler, P., \& Wareham, T. (2007). Reconceptualising the teaching-research nexus. In Proceedings of the Annual HERDSA Conference 2007: Enhancing Higher Education Theory and Scholarship (pp. 584-593). Adelaide, Australia.

Whitchurch, C. (2008). Shifting identities and blurring boundaries: The emergence of third space professionals in UK higher education. Higher Education Quarterly, 62(4), 377-396. http://dx.doi.org/10.1111/j.1468-2273.2008.00387.x

Yifeng, L. (2006). Exploration on the modularization design of curriculum in higher vocational education [In Chinese]. Vocational and Technical Education, 7(13), 45-46. 
Connor, A. M. 